\title{
Psychometric Validation of Exercise Motivation for Health Scale (EMHS)
}

\author{
Chenghong Hu${ }^{1}$, Ami Kojima1,2, Urusla Athenstaedt ${ }^{3}$, Yoshiko Kato ${ }^{{ }^{*}}$ \\ ${ }^{1}$ Graduate School of Human Development and Environment, Kobe University, Kobecity, Japan \\ ${ }^{2}$ Human Nursing, The University of Shiga Prefecture, Hikone, Japan \\ ${ }^{3}$ Institute of Psychology, University of Graz, Graz, Austria \\ Email: *ykatou@crystal.kobe-u.ac.jp
}

How to cite this paper: $\mathrm{Hu}, \mathrm{C} . \mathrm{H} .$, Kojima, A., Athenstaedt, U. and Kato, Y. (2017) Psychometric Validation of Exercise Motivation for Health Scale (EMHS). Open Journal of Social Sciences, 5, 274-287. https://doi.org/10.4236/jss.2017.510024

Received: September 27, 2017

Accepted: October 28, 2017

Published: October 31, 2017

Copyright (C) 2017 by authors and Scientific Research Publishing Inc. This work is licensed under the Creative Commons Attribution International License (CC BY 4.0).

http://creativecommons.org/licenses/by/4.0/

\section{Open Access}

\begin{abstract}
Objective: The main purpose of this study was to create a Japanese version of the exercise motivation for health scale (EMHS) and examine its psychometric validation. Methods: In study 1, participants were 532 Japanese residents $(\mathrm{M}=$ $42.82 \pm 13.29,275$ males 257 females). A questionnaire (29 items) modified from the motivation for regulation of eating behavior scale (REBS) was completed. In study 2, participants were $679(\mathrm{M}=42.82 \pm 13.29,296$ males and 383 females aged between 20 - 85) Japanese residents. Well-being, social support, and stage of change in transtheoretical model (TTM) were used as criterion to test the validity of EMHS. Results: Study 1 reported that the principal component analysis (PCA) of the EMHS revealed good construct validity. The Cronbach's alpha coefficient of the 6 subscales ranged from 0.77 to 0.89 . Study 2 indicated convergent and discriminant validity on relationship between well-being and stage of change. A relatively high compatibility (GFI $=0.91$, AGFI $=0.87$, CFI $=0.93$, RMSEA $=0.08$ ) was observed. Two significant differences between gender groups were found in the sample, a higher autonomous regulation on women, and a higher amotivation on men. Conclusion: The results suggested that the Japanese version of EMHS is reliable and valid, and can be used as a tool for measuring the motivation to exercise for health.
\end{abstract}

\section{Keywords}

Motivation, Exercise, Health, Scale

\section{Introduction}

Over the past century, although historically medical and public health efforts have focused on the length of life, increased health-care costs associated with improved longevity and "lifestyle diseases" place growing pressure on individu- 
als to assume a more active role in managing their health and improving their quality of life [1]. Current public health recommendations focus on diseases self-management and on self-regulation. Exercise regulation, which can be used to prevent and treat a variety of physical and psychological diseases [2] [3], is one such domain in which individuals can positively influence people's health and well-being. In this context people engage exercise for health. It was reported that health motivation promotes autonomous exercise regulation and participation [4]. In addition, even though people exercise for health, there are some different situations. For example, some people don't like exercise for competition, and they can enjoy exercise for health. While some people are motivated exercise for health by expectation from others. There are some kinds of exercise motivations for health that should be further to examine.

To help us more effectively encourage regular and adequate exercise, recent research has sought to improve our understanding of individuals' motivations for physical activity. Clearly, motivational processes can be studied in a terms of underlying mechanisms in people's brains. But meanwhile it is also a function of the more proximal sociocultural conditions which influence not only what people do but also how they feel. Therefore, most theories of human motivation have focused on the effects of social environments, including the rewards, incentives, and relationships inherent in them, and have assumed that more motivation, however catalyzed, will yield greater achievement and more successful functioning [5] [6]. In contrast, self-determination theory (SDT) has maintained that there are different types of motivation-specifically, autonomous and controlled motivation-and that the type of motivation is generally more important than the amount in predicting life's important outcomes [7]. SDT conceptualizes a continuum ranging from extrinsic to intrinsic motivation characterized by perceived locus of causality and corresponding processes [8]. On the basis of this conceptualization, some scales to measure exercise motivation were developed based on SDT [9]-[14]. However, among these scales, with exercise motivations, not all of them are related to health.

To measure motivation for health behavior, Pelletier et al. (2004) developed the initial version of the Regulation of Eating Behavior Scale (REBS; 24 items) on the basis of the SDT to help people maintain healthy eating behaviors and integrate them into their lifestyles. The REBS was able to predict consumption of total dietary fat and improve biological indicators of low-density lipoprotein cholesterol (LDL-cholesterol) and total cholesterol/high-density lipoprotein cholesterol (TC/HDL-cholesterol) levels as well as decreases in mean body weight [15]. Recently, Kato et al. (2013a) translated the REBS into Japanese and developed its modified version called the Motivation for Healthy Eating Scale (MHES) that assesses the motivational orientation toward healthy dietary regulation. The MEHS focuses on healthy eating attitudes, subjective health and body mass index (BMI) [16]. Particularly strong autonomous motivation was closely correlated with a balanced diet, a positive attitude toward having breakfast, and better 
subjective health. HDL-cholesterol level was correlated with autonomous motivation positively and with amotivation negatively [17]. MHES has good psychometric validity to measure healthy eating motivation.

Both eating and exercise for health are important lifestyle habits for health. In this study, we would like to offer some thoughts on the work by Kato et al. (2013a) and modify the MHES to develop exercise motivation for health scale (EMHS). In addition, the MHES includes 29 items. A package of 29 items questionnaire is a huge quantity for allowing the inclusion in larger survey studies with other primary purposes. Specifically, a survey to gather information not only on exercise but also eating behavior and mental health aspects, which would be conventional in the field of health promotion, could easily become unwieldy.

Thus, in Study 1, we created an exercise motivation for health scale (EMHS) comprising 18 items and tested its psychometric properties. Subsequently, reduced subscales were examined for validity and reliability. Lastly, the validity of the scale was further examined among Japanese people in Study 2.

\section{Study 1}

\subsection{Participants}

1227 citizens were asked to participate in the survey, which resulted in 551 samples return (44.9\%). The effective recovery of 532 (96.6\%) was carried onto the next work. In other word, 532 Japanese volunteers $($ male $=275$, female $=257)$ from $M$ city were completed the questionnaire, normally aged 21 to 76 years $(M=$ $42.82, \mathrm{SD}=13.29)$. The average BMI for the participants was $22.15( \pm 3.02)$. The participants received information about the questionnaire, completed the questionnaire anonymously, and returned it in a sealed envelope. They did not receive any incentives for their participation in this study. This study was approved by the Human Ethics Committee of faculty of Human Nursing in the University of Shiga Prefecture.

\subsection{Measurements}

Exercise Motivation for Health Scale (EMHS): The initial version of the regulation of eating behavior scale (REBS) is used to assess motives for regulating eating behavior. It comprises six subscales: "intrinsic motivation", "integrated regulation", "identified regulation", "introjected regulation", "external regulation" and "amotivation" (a total of 29 items). Participants rank statements along a seven-point continuum from 1 (does not correspond at all) to 7 (corresponds exactly) [16]. This scale has been translated into Japanese and the Japanese version has been tested and validated successfully among college students [16]-[18]. In this study, on the basis of the work by Kato et al. (2013a), the scale was modified to focus more on exercise behavior for health. Its content validity was confirmed by two health psychologists. Items were presented in random order. 


\subsection{Data Analysis}

To confirm the contractual validity firstly, covariance structure analysis of the multi-factor model was performed with 29 items. Then, the principal component analysis (PCA) was performed on the version of the EMHS with 29 items. To reduce the number of items, the second PCA was performed with the three highest factor loading items from the results of the first PCA. Alpha reliabilities (Cronbach's alpha) were computed as a measure of the internal consistency of dimensions. The Statistical Package for the Social Sciences (SPSS) ver. 23 was used for all analyses.

\subsection{Results}

The results of covariance structure analysis showed good adaptation towards SDT structural model. The indexes of adaptation of 29 items EMHS were GFI = $0.89, \mathrm{AGFI}=0.83, \mathrm{CFI}=0.93$, and RMSEA $=0.07$.

PCA was performed on each subscale of the EMHS separately. Factor loading were above 0.543 . Each subscale was confirmed to assess one dimension. The number of items was reduced to three for each of the six subscales by selecting items that loaded exclusively on their appropriate factors. Results of the second PCA are presented in Table 1. Evaluation of the internal consistency of the subscales was revealed to be adequate. Cronbach's alpha ranged from 0.77 to 0.89 .

In summary, the purpose of study 1 was to develop the items of the EMHS and to evaluate its measurement properties using SDT [7]. The results provided evidence supporting the content and construct validity of the EMHS and each of its six subscales: "intrinsic motivation", "integrated regulation", "identified regulation", "introjected regulation", "external regulation" and "amotivation”. Each subscale includes three items for a total of 18 items.

\section{Study 2}

Study 2 aimed to further examine the criterion validity of the EMHS among Japanese people. In addition to the EMHS, social support, well-being, and stage of change toward exercise were measured because the relations between motivation and these factors are significantly predictable.

The satisfaction of three basic psychological needs, namely, autonomy, competence, and relatedness, is suggested to be essential for psychological well-being [8]. In particular, satisfaction of these needs leads to more autonomous forms of motivation and well-being [19]. Furthermore, it is reported that the degree of autonomous motivation can predict well-being [20]. The relation between autonomous motivation and well-being is expected to be significant.

Relatedness has been identified as one of the innate physical needs that are the basis for self-motivation [8]. Social support is reported to have a particularly strong association with higher levels of physical activity [21] [22], showing that it affects internal and external motivation [23]. Another investigation clarified 
Table 1. PCA results for 18 items of the EMHS and Cronbach's Alpha for each subscale.

\begin{tabular}{|c|c|c|}
\hline Items & $\begin{array}{l}\text { Factor } \\
\text { loading }\end{array}$ & Contribution \% \\
\hline \multicolumn{3}{|l|}{ Intrinsic motivation $(\alpha=0.86)$} \\
\hline I take pleasure in fixing healthy exercise. & 0.898 & \multirow{3}{*}{78.62} \\
\hline I like to find new way to create exercises that are good for health. & 0.882 & \\
\hline It is fun to create exercises that are good for my health. & 0.880 & \\
\hline \multicolumn{3}{|l|}{ Integrated regulation $(\alpha=0.89)$} \\
\hline Exercising healthy is congruent with other important aspects of my life. & 0.928 & \multirow{3}{*}{82.34} \\
\hline Regulating my exercise behaviors has become a fundamental part of who I am. & 0.926 & \\
\hline Exercising healthy is base of my life. & 0.867 & \\
\hline \multicolumn{3}{|l|}{ Identified regulation $(\alpha=0.84)$} \\
\hline I believe it will make my mind and body comfortable. & 0.875 & \multirow{3}{*}{75.45} \\
\hline Is a way to ensure long-term health benefits. & 0.870 & \\
\hline I believe it's a good thing I can do to feel better about myself in general & 0.861 & \\
\hline \multicolumn{3}{|l|}{ Introjected regulation $(\alpha=0.77)$} \\
\hline I would feel ashamed of myself if I was not exercising healthy. & 0.869 & \multirow{3}{*}{68.54} \\
\hline I would be humiliated I was not in control of my exercise behaviors. & 0.813 & \\
\hline I feel it is shame not to be able to show healthy exercise habits. & 0.801 & \\
\hline \multicolumn{3}{|l|}{ External regulation $(\alpha=0.84)$} \\
\hline It is expected of me. & 0.923 & \multirow{3}{*}{76.27} \\
\hline Other people close to me insist that I do. & 0.917 & \\
\hline Other people sugestions to keep healthy exercise habits. & 0.772 & \\
\hline \multicolumn{3}{|l|}{ Amotivation $(\alpha=0.86)$} \\
\hline I can't really see I'm getting out of it & 0.903 & \multirow{3}{*}{77.84} \\
\hline I don't really know. I truly have the impression that I'm wasting my time trying to regulate my exercise behaviors. & 0.888 & \\
\hline I don't really know why I bother. & 0.855 & \\
\hline
\end{tabular}

that perception of social support affected the degree of autonomous motivation. Social support is thus expected to have a significant positive relation with autonomous motivation [20].

Prochaska and Clemente developed the Transtheoretical model (TTM) [24], which has been adopted as an appropriate and possibly effective basis for lifestyle intervention. The TTM identifies five stages of change: Precontemplation, Contemplation, Preparation, Action, and Maintenance based on readiness for the targeted behavior. Exercise behavior has been confirmed to follow the pattern outlined by these stages of change [25]. Accordingly, in this study, it is hypothesized that each degree of motivation for exercise corresponds to one of the stages of change.

\subsection{Participants}

In this study, questionnaire was conducted among 1039 citizens and 1004 
(96.6\%) of them returned the questionnaire. Of those responding, 679 participants $($ male $=296$, female $=383$ ) within ages ranging from 20 to 85 years, completed the questionnaire. Of these, 122 were aged below 30 years, 223 were aged from 30 to 39 years, 145 were aged from 40 to 49 years, 132 were aged from 50 to 59 years, and 57 were aged 60 or over. The average BMI for the participants was $22.00( \pm 3.03)$. They did not receive any incentive for their participation in this study.

\subsection{Measurements}

Exercise Motivation for Health Scale (EMHS): Participants completed the 18 items on the EMHS as the index of SDT's exercise regulation for health. The EMHS contains six subscales measuring "intrinsic motivation", "integrated regulation", "identified regulation", "introjected regulation", "external regulation" and "amotivation". The following instructions were provided: "We would like to know what you think about exericise for health. Please check the appropriate item number that is closest to your opinion." Participants answered each item on a six-point scale ranging from 1 (don't agree at all) to 6 (agree completely).

Well-being: We used the Ikigai scale (Ikigai-9) to measure well-being, defined as a positive purpose, a sense of fulfillment, and social relationships, and its effects on mentalhealth. The concept of Ikigai is a Japanese understanding of well-being. The reliability and validity of this scale had been confirmed [26]. The Ikigai-9 comprises three subscales (nine items), namely, "Challenge", "Life Satisfaction", and "Social Role", and a five-point Likert scale was used from 1 (almost always true) to 5 (almost never true). Internal consistency for the current sample was 0.83 .

Multidimensional Scale of Perceived Social Support (MSPSS): This scale subjectively evaluates the participant's perceived social support from family, friends, and significant others [27]. The psychometric properties of this scale have been examined among Japanese people [28]. The MSPSS comprises 12 items containing three subscales: support from family, support from friends, and support from significant others. Respondents indicate their agreement with each item on a seven-point response scale from 1 (disagree strongly) to 7 (agree strongly). Higher scores indicate stronger perceived social support. The MSPSS has good internal reliability and factor analysis has confirmed the suitability of the three-subscale structure [28]. In this study, Cronbach's $\alpha$ were 0.88 - 0.92 .

Stages of Change to the Exercise Scale (SCES): This scale consisted of a single question intended to sort the participants into five categories on the basis of the Transtheoretical Model (TTM) of behavior change [24]. The validity of SCES has been demonstrated by Marcus et al. [29]. The SCES resembles a ladder with each rung representing a different stage. It includes the following stages: 1) Precontemplation: Those who do not anticipate the beginning of exercise in the next six months; 2) Contemplation: Individuals in this stage may seriously intend to exercise within the next six months or are at least contemplating exer- 
cising within the next six months; 3) Preparation: Those planning to change their behavior in the near future and already preparing for action; 4) Action: Individuals in this stage may exercise regularly but have been doing so for less than six months; and 5) Maintenance: Individuals in this stage exercise regularly and have done so for more than six months. From among these five stages, participants in this study were asked to pick the one that most accurately described their current interest in exercise or/and exercise behavior.

\subsection{Statistical Analysis}

Covariance structure analysis of the multi-factor model was performed on the EMHS to confirm the structure of the scale by Amos ver. 23. Additionally, the motivation score for autonomous regulation of exercise behavior was computed by the relative autonomy index (RAI). Intrinsic motives are highly internal, whereas motives pertaining to strong external controls are weighted in the externally motivated direction. The results can be summarized as a single score measuring the degree to which an individual's decisions regarding exercise for health are self-determined. The "intrinsic motivation" scale is weighted 2, the "identified regulation" scale 1, the "introjected regulation" scale -1 , and the "external regulation" scale -2 . This weighting procedure is justified by the simplex structure of the measurement [30] which was calculated using the formulation: RAI $=2 \times$ (intrinsic motivation $)+($ identified regulation $)-($ introjected regulation) $-2 \times$ (external regulation). It has been reported that RAI can predict the ideal form of support for education [31] [32]. SPSS ver. 23 and Amos ver. 23 were used for all analysis.

\subsection{Results}

Covariance structure analysis of the multi-factor model was performed. The indexes of adaptation were GFI $=0.91, \mathrm{AGFI}=0.87, \mathrm{CFI}=0.93$, and RMSEA $=$ 0.08 . The Cronbach's alpha coefficients of six subscales ranged from 0.82 to 0.89 in this study.

Pearson correlations were calculated among the six subscales, RAI, social support, and well-being (Table 2). The correlations among the six factors of the EMHS are presented in Table 2. The results showed that there was a very strong positive correlation between intrinsic motivation and integrated regulation $(\mathrm{r}=$ $0.708, \mathrm{p}<0.001)$, a positive correlation between intrinsic motivation, identified regulation and integrated regulation (intrinsic motivation and identified regulation, $\mathrm{r}=0.495, \mathrm{p}<0.001$; identified regulation and integrated regulation, $\mathrm{r}=$ $0.612, \mathrm{p}<0.001$ ), and weak positive correlations between introjected regulation and intrinsic motivation $(\mathrm{r}=0.181, \mathrm{p}<0.001)$, between external regulation and intrinsic motivation $(\mathrm{r}=0.178, \mathrm{p}<0.001)$, between integrated and introjected regulation $(r=0.251, p<0.001)$, between introjected and external regulation $(r=$ $0.290, \mathrm{p}<0.001)$, and between introjected and external regulation $(\mathrm{r}=0.171, \mathrm{p}<$ 0.001 ). There were negative correlations between amotivation and all other factors except external regulation (e.g., intrinsic motivation and amotivation, $r=$ 
Table 2. Correlations among the six subscales of EMHS, RAI and well-being.

\begin{tabular}{|c|c|c|c|c|c|c|c|c|c|c|}
\hline & \multirow{2}{*}{ Integ. } & \multirow{2}{*}{ Identi. } & \multirow{2}{*}{ Intro. } & \multirow{2}{*}{ Ex. } & \multirow{2}{*}{ Amo } & \multirow{2}{*}{ RAI } & \multirow{2}{*}{ Well-being } & \multicolumn{3}{|c|}{ Social support } \\
\hline & & & & & & & & Others & Family & Friends \\
\hline Intrin. & $0.708^{* * *}$ & $0.495^{\star * *}$ & $0.181^{\star * *}$ & $0.178^{\star * *}$ & $-0.293^{* * *}$ & $0.578^{\star * *}$ & $0.348^{* * *}$ & $0.213^{* * *}$ & $0.202^{\star * *}$ & $0.214^{* * *}$ \\
\hline Integ. & & $0.612^{* * *}$ & $0.251^{\star * *}$ & $0.290^{\star * *}$ & $-0.397^{\star \star \star}$ & $0.330^{* * *}$ & $0.319^{* * *}$ & $0.206^{* * *}$ & $0.193^{\star * *}$ & $0.212^{\star * *}$ \\
\hline Identi. & & & -0.029 & $0.171^{\star \star \star}$ & $-0.630^{\star * *}$ & $0.452^{\star * *}$ & $0.351^{\star \star \star}$ & $0.245^{\star * *}$ & $0.243^{\star \star \star}$ & $0.231^{\star * *}$ \\
\hline Intro. & & & & $0.350^{* * *}$ & $0.303^{* * *}$ & $-0.410^{* * *}$ & -0.006 & -0.047 & -0.072 & -0.005 \\
\hline Ex. & & & & & 0.036 & $-0.614^{* * *}$ & $0.105^{\star *}$ & 0.075 & $0.080^{*}$ & 0.074 \\
\hline Amo. & & & & & & $-0.449^{* * *}$ & $-0.199^{* * *}$ & $-0.149^{* * *}$ & $-0.161^{\star * *}$ & $-0.117^{\star *}$ \\
\hline RAI & & & & & & - & $0.236^{* * *}$ & $0.157^{\star * *}$ & $0.154^{\star * *}$ & $0.143^{* * *}$ \\
\hline well-being & & & & & & & & $0.491^{\star * *}$ & $0.411^{\star * *}$ & $0.421^{* * *}$ \\
\hline
\end{tabular}

Note: Intrin.: Intrinsic motivation; Integ.: Integrated regulation; Identi.: Identified regulation; Intro.: Introjected regulation; Ex.: External regulation; Amo.: Amotivation; ${ }^{* *}: \mathrm{p}<0.001,{ }^{* *}: \mathrm{p}<0.01,{ }^{*}: \mathrm{p}<0.05$.

$-0.293, \mathrm{p}<0.001)$. No correlation was found between external regulation and amotivation.

Meanwhile, correlations between motivation, RAI, well-being, and social support can be seen in Table 2. Autonomous motivation and RAI were related with well-being and social support positively (e.g., intrinsic motivation and RAI, $\mathrm{r}=0.578, \mathrm{p}<0.001$; intrinsic motivation and well-being, $\mathrm{r}=0.348, \mathrm{p}<0.001$, or identified regulation and social support from others, $r=0.245, p<0.001$ ). Amotivation, on the contrary, was negatively associated with the other factors (e.g., amotivation and RAI, $\mathrm{r}=-0.449, \mathrm{p}<0.001$, or amotivation and well-being, $\mathrm{r}=$ $-0.199, \mathrm{p}<0.001)$. External regulation had weak positive relations with well-being and social support.

Descriptive data divided into sex-based groups are presented in Table 3. A $\mathrm{t}$-test revealed that men reported lower identified regulation $(\mathrm{t}=2.80, \mathrm{p}<0.01)$ and higher amotivation $(t=2.35, \mathrm{p}<0.05)$ compared with women. There were no significant differences among the other four factors.

In this study, participants were asked to respond to the SCES per their current degree of interest and action in exercise and actual involvement in exercise, mainly with regard to the length of time they had been practicing their exercise. According to the stage they selected, the volunteers were divided into five groups, namely, Precontemplation, Contemplation, Preparation, Action, and Maintenance. A one-way ANOVA was used to analyze their motivation for regulation of exercise behavior. The percentages of people in each stage of change were as follows: 1) $21.06 \%$ in Precontemplation, 2) $36.38 \%$ in Contemplation, 3) $13.84 \%$ in Preparation, 4) $10.46 \%$ in Action, and 5) $18.26 \%$ in Maintenance. As Table 4 depicts, those in Maintenance showed the highest scores for autonomous motivation and RAI. Those in Precontemplation revealed the high scores for amotivation and the lowest scores for motivation and RAI. Scores for controlled motivation (introjected and external regulation) were higher in the Preparation stage. 
Table 3. Mean value and results of $\mathrm{t}$-test by gender.

\begin{tabular}{|c|c|c|c|c|c|c|c|}
\hline & \multicolumn{2}{|c|}{ Total $(\mathrm{N}=679)$} & \multicolumn{2}{|c|}{ Male $(\mathrm{N}=296)$} & \multicolumn{2}{|c|}{ Female $(\mathrm{N}=383)$} & \multirow{2}{*}{$\mathrm{p}$} \\
\hline & M & $\mathrm{SD}$ & M & SD & M & SD & \\
\hline Intrinsic motivation & 3.68 & 1.15 & 3.71 & 1.08 & 3.66 & 1.21 & 0.550 \\
\hline Integrated regulation & 3.97 & 1.21 & 3.91 & 1.21 & 4.02 & 1.22 & 0.252 \\
\hline Identified regulation & 4.85 & 0.91 & 4.74 & 0.91 & 4.93 & 0.91 & 0.005 \\
\hline Introjected regulation & 2.31 & 1.04 & 2.39 & 1.01 & 2.25 & 1.06 & 0.076 \\
\hline External regulation & 3.28 & 1.23 & 3.34 & 1.19 & 3.22 & 1.26 & 0.206 \\
\hline Amotivation & 1.97 & 0.92 & 2.06 & 0.93 & 1.89 & 0.9 & 0.019 \\
\hline RAI & 3.35 & 3.69 & 3.08 & 3.49 & 3.56 & 3.83 & 0.285 \\
\hline well-being & 3.33 & 0.67 & 3.26 & 0.69 & 3.39 & 0.65 & 0.052 \\
\hline
\end{tabular}

Table 4. Mean value of EMHS subcale and results of one-way ANOVA by stage of change.

\begin{tabular}{|c|c|c|c|c|c|c|c|c|c|c|c|c|}
\hline & \multirow{3}{*}{\multicolumn{2}{|c|}{$\begin{array}{c}\text { Precontemplation } \\
\mathrm{a}\end{array}$}} & \multirow{2}{*}{\multicolumn{2}{|c|}{$\frac{\text { Contemplation }}{\mathrm{b}}$}} & \multirow{2}{*}{\multicolumn{2}{|c|}{$\begin{array}{c}\text { Preparation } \\
\mathrm{c}\end{array}$}} & \multirow{2}{*}{\multicolumn{2}{|c|}{$\frac{\text { Action }}{\mathrm{d}}$}} & \multirow{2}{*}{\multicolumn{2}{|c|}{$\frac{\text { Maintenance }}{\mathrm{e}}$}} & \multirow{4}{*}{$\mathrm{F}$} & \multirow{4}{*}{ Bonferroni } \\
\hline & & & & & & & & & & & & \\
\hline & & & & & & & & & & & & \\
\hline & M & SD & M & SD & M & SD & M & SD & M & $\mathrm{SD}$ & & \\
\hline Intrin. & 2.89 & 1.09 & 3.57 & 0.96 & 4.03 & 1.10 & 4.04 & 1.06 & 4.34 & 1.10 & $38.33^{* * *}$ & $\mathrm{a}<\mathrm{b}<\mathrm{c}, \mathrm{d}, \mathrm{e}$ \\
\hline Integ. & 3.25 & 1.11 & 3.97 & 1.05 & 4.35 & 1.26 & 4.06 & 1.15 & 4.45 & 1.25 & $22.32^{\star * *}$ & $\begin{array}{c}\mathrm{a}<\mathrm{b}, \mathrm{c}, \mathrm{d}, \mathrm{e} ; \\
\mathrm{b}<\mathrm{e}\end{array}$ \\
\hline Identi. & 4.46 & 1.03 & 4.81 & 0.87 & 4.97 & 0.87 & 5.00 & 0.83 & 5.20 & 0.76 & $13.03^{\star * *}$ & $\begin{array}{c}\mathrm{a}<\mathrm{b}, \mathrm{c}, \mathrm{d}, \mathrm{e} ; \\
\mathrm{b}<\mathrm{e}\end{array}$ \\
\hline Intro. & 2.06 & 1.01 & 2.33 & 0.96 & 2.60 & 1.08 & 2.21 & 0.97 & 2.39 & 1.17 & $4.34^{\star \star}$ & $\mathrm{a}<\mathrm{c}$ \\
\hline Ex. & 2.96 & 1.28 & 3.38 & 1.14 & 3.71 & 1.07 & 3.22 & 1.32 & 3.15 & 1.33 & $6.22^{* * *}$ & $\begin{array}{c}\mathrm{a}<\mathrm{b}<\mathrm{c} \\
\mathrm{e}<\mathrm{c}\end{array}$ \\
\hline Amo. & 2.23 & 1.04 & 2.00 & 0.87 & 1.95 & 0.93 & 1.89 & 0.80 & 1.65 & 0.82 & $6.99^{* * *}$ & $\mathrm{a}, \mathrm{b}>\mathrm{e}$ \\
\hline RAI & 2.27 & 3.85 & 2.85 & 3.45 & 3.03 & 3.22 & 4.45 & 3.22 & 5.20 & 3.78 & $14.89^{* * *}$ & $\mathrm{a}, \mathrm{b}<\mathrm{d}, \mathrm{e} ; \mathrm{c}<\mathrm{e}$ \\
\hline
\end{tabular}

Note: Intrin.: Intrinsic motivation; Integ.: Integrated regulation; Identi.: Identified regulation; Intro.: Introjected regulation; Ex.: External regulation; Amo.: Amotivation; ${ }^{* * *}: \mathrm{p}<0.001,{ }^{* *}: \mathrm{p}<0.01,{ }^{*}: \mathrm{p}<0.05$.

\section{Discussion}

Based on the regulation of eating behavior scale and SDT, this study selected Japanese people as subjects and developed a modified version of exercising for health, which comprised six factors (18 items) by PCA, namely "intrinsic motivation", "integrated regulation", "identified regulation", "introjected regulation", "external regulation" and "amotivation". The results suggested that the EMHS is a suitable measurement of exercise motivation for the people. Compared to the work by Wilson et al. [11], the items of EMHS reduced in order to obtain a more easily applicable (short) version. Furthermore, in Study 2, we cross-validated the EMHS with a new sample to confirm its criterion validity. The adaptation indexes of covariance structure analysis indicated a relatively high compatibility between the model and sample data. The results indicated a relatively high compatibility between the scale and sample data. 
SDT postulates a continuum of autonomy to order those types of motivation. Overall, adjacent subscales generally showed higher correlations (e.g., intrinsic motivation and integrated regulation, $r=0.708$ ) than the subscales farther apart (e.g., intrinsic motivation and identified regulation, $r=0.495$, or intrinsic motivation and amotivation, $r=-0.293, \mathrm{p}<0.01$ ). These results were in line with a prior study [15] and supported the presence of a self-determination continuum.

Criterion validity between the EMHS, social support, and well-being were demonstrated with the Pearson correlation coefficient. As expected, social relationship and well-being related to the autonomous regulation positively, whereas related amotivation negatively; i.e., the exercise participant with a higher positive purpose, a sense of being full, and social support is more sufficiently motivated to be physically active. SDT researchers devoted to find the conditions that facilitate autonomous motivation [8] [19]. On the basis of empirical and theoretical considerations, we proposed that conditions of the basic psychological needs would facilitate autonomous motivation [8]. Three psychological needs "competence", "autonomy" and "relatedness" were reported to facilitate autonomous motivation [33]. Per the definition of mental health by WHO, satisfaction of basic psychological needs is considered a state of well-being [20]. As a result, it was reported that well-being related to autonomous motivation positively and amotivation negatively. Moreover, when we consider about psychological needs and well-being, relationships with others are important. In this study, emotional social supports correlated positively with autonomous motivation and negatively with amotivation. Those links also point to the validity of the EMHS.

In this study, we also investigated the participant's intention and the current degree of involvement in physical activity using SCES. Results suggested that the participants with higher autonomous exercise regulation (intrinsic motivation, integrated regulation, and identified regulation) exhibited higher intention and could persist in exercise behavior. For example, in the different stages, the participants in Maintenance with the most interest and involvement in exercise behavior achieved the highest score in autonomous and controlled regulation. In contrast, those in Precontemplation with no intention and exercise achieved the lowest score in almost all of the subscales except amotivation. In fact, the level of reflective self-endorsement and willingness associated with a behavior or class of behaviors should be associated with greater persistence [34]. Thus, our results show consistent support for the positive relation between more autonomous forms of motivation and higher degree of interest and participation in exercise behaviors. These results were in line with the previous study [35] [36].

Regarding gender, there were significant differences in motivations for a healthy life-style [37]. Women reported the reasons of health-related activities as "duty" and "the feeling of staying young" more than men. Two significant differences between the groups were found in this study. The scores of identified regulation were higher in women than men. Women might value health more than men. Men showed less autonomous regulation (mainly in identified regula- 
tion) and higher amotivation compared with women in this sample. Motivation for healthy eating also showed similar results [18]. Women revealed a higher, integrated, and introjected regulation and less amotivation than men.

\section{Conclusions}

To summarize, EMHS, with its appropriate psychometric properties, can be used to measure the exercise motivation for health. Autonomous motivation predicts good performance and maintenance of health behavior. Furthermore, we conclude that exercise motivation for health relates to social support, well-being, and stages of change to exercise. Since there isn't exercise motivation related to health in academic field and health is very important for human. So this study presented a short version to investigate exercise motivation for health which is suitable for Japanese, and may contribute to the literature on exercise with examining how some social and psychological infectors affect our exercise for health. And we also hope that EMHS can help people maintain exercise for health.

In future, contribution of psychosocial factors toward exercise motivation for health can be clarified further and information for behavior change toward exercising for health will be accumulated using EMHS. For example, the predictive ability of the EMHS with respect to relation with a biological indicator like metabolic syndrome was not formally validated in this study and must be tested in future research. And the participants in present study are aged 20 years or more. Since gaining autonomous motivation for exercise is considered to begin at a younger age, EMHS should be used to further examine the validation and reliability on younger participants.

\section{Acknowledgements}

The present research was financially supported by JSPS KAKENHI Grant Number 15k00871. The authors would like to thank participants for their involvement in this study.

\section{References}

[1] Teixeira, P.J., Patrick, H. and Mata, J. (2011) Why We Eat What We Eat: The Role of Autonomous Motivation in Eating Behavior Regulation. Nutrition Bulletin, 36, 102-107. https://doi.org/10.1111/j.1467-3010.2010.01876.x

[2] Warburton, D.E.R, Nicol, C.W. and Bredin, S.S.D. (2006) Health Benefit of Physical Activity: The Evidence. Canadian Medical Association Journal, 174, 801-809. https://doi.org/10.1503/cmaj.051351

[3] WHO (2004) Global Strategy on Diet and Physical Activity. WHO, Geneva.

[4] Ingledew, D.K., Markland, D. and Ferguson, E. (2009) Three Levels of Exercise Motivation. Applied Psychology: Health and Well-Being, 1, 336-355. https://doi.org/10.1111/j.1758-0854.2009.01015.x

[5] Bandura, A. (1996) Self Efficacy: The Exercise of Control. Freeman, New York.

[6] Baumeister, R.F. and Vohs, K.D. (2007) Self-Regulation, Ego Depletion, and Moti- 
vation. Social and Personality Psychology Compass, 1, 1-14. https://doi.org/10.1111/j.1751-9004.2007.00001.x

[7] Deci, E.L. and Ryan, R.M. (1985) Intrinsic Motivation and Self-Determination in Human Behavior. Plenum Press, New York. https://doi.org/10.1007/978-1-4899-2271-7

[8] Ryan, R.M. and Deci, E.L. (2000) Self-Determination Theory and the Facilitation of Intrinsic Motivation, Social Development, and Well-Being. American Psychologist, 55, 68-78. https://doi.org/10.1037/0003-066X.55.1.68

[9] Mullan, E., Markland, D.A. and Ingledew, D.K. (1997) A Graded Conceptualisation of Self-Determination in the Regulation of Exercise Behaviour: Development of a Measure Using Confirmatory Factor Analytic Procedures. Personality and Individual Differences, 23, 745-752. https://doi.org/10.1016/S0191-8869(97)00107-4

[10] Markland, D. and Tobin, V. (2004) A Modification to the Behavioural Regulation in Exercise Questionnaire to Include an Assensment of Amotivation. Journal of Sport \& Exercise Psychology, 26, 191-196. https://doi.org/10.1123/jsep.26.2.191

[11] Wilson, P.M., Rodgers, W.M., Loitz, C.C. and Scime, G. (2006) "It's Who I Am ... Really!" The Importance of Integrated Regulation in Exercise Contexts. Journal of Applied Biobehaviorak Research, 11, 79-104. https://doi.org/10.1111/j.1751-9861.2006.tb00021.x

[12] Karin, W.J., Magnus, L. and Andreas, I. (2015) Need Satisfaction, Motivational Regulations and Exercise: Moderation and Mediation Effects. International Journal of Behavioral Nutrition and Physical Activity, 12, 67-78.

https://doi.org/10.1186/s12966-015-0226-0

[13] Matsumoto, Y., Takenaka, K. and Takaie, N. (2003) Development of the Exercise Motivation Scale for Exercise Adherence Based on self-Determination Theory: The Reliability and Validity. Japan Society of Health Promotion, 5, 120-129.

[14] Fujita, T., Sato, Y. and Moriguchi, T. (2010) A Study of Exercise Motivation Based on Self-Determination Theory. Bulletin of the Faculty of Education, Kagoshima University, 61, 61-71.

[15] Pelletier, L.G., Dion, S.C., Slovinec-D'Angelo, M. and Reid, R. (2004) Why Do You Regulate What You Eat? Relationships between Forms of Regulation, Eating Behaviors, Sustained Dietary Behaviors Change, and Psychological Adjustment. Motivation and Emotion, 28, 245-277. https://doi.org/10.1023/B:MOEM.0000040154.40922.14

[16] Kato, Y., Iwanaga, M., Roth, R., Hamasaki, T. and Greimel, E. (2013a) Psychometric Validation of the Motivation for Healthy Eating Scale (MHES). Psychology, 4, 136-141. https://doi.org/10.4236/psych.2013.42020

[17] Kato, Y. and Kojima, A. (2015) Relationship between Biological Indicator of Metabolicsyndrome and Motivation for Healthy Eating and Exercise for Health. Japanese Journal of Public Health, 62, 273.

[18] Kato, Y., Nishida, M., Tanaka, Y. and Kawabata, T. (2013b) The Relationship between Motivation for Healthy Eating and Attitudes toward Childhood Eating Habits among University Students. Japanese Journal of School Health, 54, 507-519.

[19] Van den Broeck, A., Ferris, D.L., Chang, C. and Rosen, C. (2016) A Review of Self-Determination Theory's Basic Psychological Needs at Work. Journal of Management, 42, 1195-1229. https://doi.org/10.1177/0149206316632058

[20] Niemic, C.P., Lynch, M.F., Vansteenkiste, M., Bernstein, J., Deci, E.L. and Ryan, R.M. (2006) The Antecedents and Consequences of Autonomous Self-Regulation 
for College: A Self-Determination Theory Perspective on Socialization. Journal of Adolescence, 29, 761-775. https://doi.org/10.1016/j.adolescence.2005.11.009

[21] Sharma, M., Sargent, L. and Stacy, R. (2005) Predictors of Leisure-Time Physical Activity among African American Women. American Journal of Health Behavior, 29, 352-359. https://doi.org/10.5993/AJHB.29.4.7

[22] Sallis, J.F., Grossman, R.M., Pinski, R.B., Patterson, T.L. and Nader, P.R. (1987) The Development of Scales to Measure Social Support for Diet and Exercise Behaviors. Preventive Medicine, 16, 825-836. https://doi.org/10.1016/0091-7435(87)90022-3

[23] Li, K., Lannotti, R., Haynie. D., Perlu, D. and Simons-Morton, B. (2013) Motivation and Planning as Mediators of the Relation between Social Support and Physical Activity among U.S. Adolescents: A Nationally Representative Study. International Journal of Behavioral Nutrition and Physical Activity, 11, 42. https://doi.org/10.1186/1479-5868-11-42

[24] Prochaska, J.O. and DiClemente, C.C. (1982) Transtheoretical Therapy: Toward a More Integrative Model of Change. Psychotherapy. Theory, Research and Practice, 19, 276-288. https://doi.org/10.1037/h0088437

[25] Van Sluijs, E.M.F., Van Poppel, N.M.M. and Van Mechelen, W. (2004) Stage-Based Life Style Interventions in Primary Care Are They Effective? American Journal of Preventive Medicine, 26, 330-343. https://doi.org/10.1016/j.amepre.2003.12.010

[26] Imai, T., Osada, H. and Nishi, S. (2012) The Reliability and Validity of a New Scale for Measuring the Concept of Ikigai (Ikigai-9). Japanese Journal of Public Health, 59, 433-440.

[27] Zimet, G.D., Dahlem, N.W., Zimet, S.G. and Farley, G.K. (1988) The Multidimensional Scale of Perceived Social Support. Journal of Personality, 52, 30-41.

[28] Iwasa, H., Gondo,Y., Masui, Y., Inagaki, H., Kawai, C., Ootsuka, R., Ogawa, M., Takayama, M., Imuta, H. and Suzuki, T. (2007) Validity and Relability of Japnese Version Multidimensional Scale of Perceived Social Support. Kosei no Shihyo, 54, 26-33.

[29] Marcus, B.H., Selby, C., Niaura, S. and Rossi, S. (1992) Self-Efficacy and the Stages of Exercise Behavior Change. Research Quarterly for Exercise \& Sport, 63, 60-66. https://doi.org/10.1080/02701367.1992.10607557

[30] Guttman, L. (1954) A New Approach to Factor Analysis: The Radix. In: Lazarfeld, P., Ed., Mathematical Thinking in the Social Sciences, Free Press of Glencoe, New York, 258-348.

[31] Grolnic, W.S. and Ryan, R.M. (1987) Autonomy in Children's Learning: An Experimental and Individual Difference Investigation. Journal of Personality and Social Psychology, 52, 890-898. https://doi.org/10.1037/0022-3514.52.5.890

[32] Grolnic, W.S. and Ryan, R.M. (1989) Parent Styles Associated with Children's Self-Regulation and Competence in School. Journal of Educational Psychology, 81, 143-154. https://doi.org/10.1037/0022-0663.81.2.143

[33] Deci, E.L. and Ryan, R.M. (2008) Facilitating Optimal Motivation and Psychological Well-Being across Life's Domains. Canadian Psychology, 49, 14-23. https://doi.org/10.1037/0708-5591.49.1.14

[34] Teixeira, P.J., Carraca, E.V., Markland, D., Silva, M.N. and Ryan, R.M. (2012) Exercise, Physical Activity, and Self-Determination Theory: A Systematic Review. International Journal of Behavioral Nutrition and Physical Activity, 9, 48-78. https://doi.org/10.1186/1479-5868-9-78

[35] Mullan, E. and Markland, D.A. (1997) Variations in Self-Determination across the 
Stages of Change for Exercise in Adults. Motivation and Emotion, 21, 362-752. https://doi.org/10.1023/A:1024436423492

[36] Matsumoto, H. and Takenaka, K. (2004) Motivational Profiles and Stage of Exercise Behavior Change. International Journal of Sport and Health Science, 2, 89-96. https://doi.org/10.5432/ijshs.2.89

[37] Wiesemann, A., Ludt, S., Szecsenyi, J., Scheregmann, W. and Scheidt, S. (2004) Cardiovascular Risk Factors and Motivation for a Healthy Life-Style in a German Community-Results of GP-Based Oestringen Study. Patient Education and Counseling, 55, 40-47. https://doi.org/10.1016/j.pec.2003.07.002 